\title{
POR LOS CAMINOS EVOLUTIVOS DE LA PAPA SILVESTRE Y CULTIVADA
}

René Chávez Alfaro

\section{A: Oscar Blanco Galdos, i.m.}

\section{INTRODUCCION}

Dentro del continente americano, el Perú representa una de las regiones agrícolas más ricas y antiguas. Junto con México y regiones montañosas adyacentes, constituye el asiento más importante como centro de origen de un gran número de especies y formas vegetales útiles al hombre. La papa muestra un gran ejemplo de este hecho; el rol que desempeña en la dieta de la población peruana y en la alimentación mundial es de capital importancia y al presente constituye la planta alimenticia más importante del mundo, después del arroz y el trigo.

El cultivo de la papa empezó hace miles de años, en las vertientes occidentales de los Andes peruanos, donde el Solanum tuberífero evolucionó en su remarcable diversidad genética. Cuando los europeos llegaron a América, la población andina ya era altamente dependiente de la papa cultivada. Se calcula que en todo el Tahuantinsuyo, los incas habían logrado domesticar y cultivar cerca de 3,000 variedades agrupadas en ocho especies de papa, de las cuales cerca de 1,000 se han extinguido. A la fecha, en los Andes del Perú, Bolivia y Ecuador se cultivan alrededor de 2,000 variedades nativas. Sin embargo, en muchos países del hemisferio norte y algunos países subtropicales como Australia, ios agricultores cultivan solamente una especie de papa, el Solanum tuberosum, con unas cuantas variedades. Por ejemplo, de un millón y medio de acres que se cultivan en EE.UU. y Canadá 1'200,000 son cultivadas solamente con seis variedades, y cerca de $40 \%$ de esta extensión pertenece a la variedad Russet Burbank, la cual se originó por mutación somática espontánea de otra variedad introdu';ida a Burbank a fines del siglo pasado.

Las especies nativas y primitivas que hoy en día habitan en los Andes peruanos dierón origen a la papa cultivada .Estas especies juegan un papel clave en el desarrollo de nuevas variedades con resistencia a estreses bióticos y abióticos. Asimismo hoy día representan resenvorios de genes adicionales de recursos genéticos, Aquí se enfoca en forma panorámica los caminos evolutivos, interesantes, misteriosos y controvertidos seguidos por la papa en el tiempo y el 86 espacio desde su origen tan oscuro hasta hoy

\section{SOBRE EL ORIGEN}

El origen y evolución de la papa cultivada, han sido estudiados extensivamente desde la publicación de los resultados de la expedición científica de Juzecpzuk y Bukasov a América Central y Sud América, en los años de 1925 y 1932 . Estos investigadores mostraron al mundo la inmensa variabilidad genética de las papas del Perú y Bolivia. Hay numerosas evidencias botánicas, ecológicas, geneticas y arqueológicas que llevan a concluir que en el Centro Genético Sud Americano de Vavilov se han domesticado y evolucionado especies cultivadas tuberíferas hace más de 10,000 años, tal es el caso de la papa, la oca, el olluco y la mashua y otras raices reservantes como la yuca y el camote.

El Profesor Hawkes de la Universidad de Birmingham, en su libro "Historia de la papa» publicado en 1978 , sostiene que la región situada entre el Cusco y el Lago Titicaca sería el centro de origen de la papa cultivada, porque en esta región alto andina, existe un gran número de variedades nativas y la variabilidad genética de los clones primitivos es excepcionalmente alta. La papa se habría originado allí hace 10 a 15,000 años, a partir de una especie diploide silvestre llamada Solanum canasense. Además, el número de especies silvestres de Solanum tuberíferos, morfológica y genéticamente afines a la papa cultivada, son también marcadamente altos, más que en ninguna otra región andina. De Sud América emigró la papa al resto del Altiplano, y durante el Imperio Incaico se distribuyó por todo el Tahuantinsuyo, llegando incluso al sur de Chile. La primera especie cultivada que se originó en los Andes fue la diploide Solanum stenotonum, $(2 n=$ $2 x=24=A A$ ). Esta especie se habría originado de su antecesor silvestre Solanum canasense ampliamente distribuido en el Perú. Algunas variedades primitivas lograron ser introducidas en épocas precolombinas a la zona de Chiloé, donde a través de miles de generaciones lograron su adaptación a días largos de verano 


\section{e invierno muy frío.}

Excavaciones realizadas en la zona de ChiripaPuno, han mostrado chuño que data desde hace 400 años A.C.. El Profesor P. Engel, en 1970 reportó haber realizado observaciones al microscopio electrónico de granos de almidón de papa, que data de hace 8,000 años en el valle de Chilca, Lima.

Según Salaman y Hawkes, la papa fué introducida a Europa en 1570, primeramente a España, de alli se dispersó a Inglaterra y luego fue introducida a las colonias ir.glesas de este tiempo, después de ahí pasó a Norte América, Centro América y países asiáticos. De esta manera los incas habian heredado ese material palpitante llamado papa a la agricultura mundial.

\section{SU DISEMINACION GLOBAL}

Comparando con otros cultivos, la papa es rica en calorías y proteínas por hectárea. Es también una buena fuente de importantes vitaminas, especialmente C y B y minerales. Como un cultivo económicamente rentable, es superior a muchas plantas alimenticias en producción de alimentos por hectárea y por día. Además, la papa madura en un período más corto que muchos cultivos tropicales, adaptándose a cualquier sistema de cultivo.

En los paises en vía de desarrollo, la papa no es un cultivo muy extenso; sin embargo, en los países de origen como el Perú, Bolivia, Ecuador y Colombia, es un cultivo principal, donde la capa arable está mayormente a más de $3,000 \mathrm{~m}$. de altitud. En la actualidad se cultiva 22 millones de hectáreas en el mundo y solamente el $11 \%$ en los países del tercer mundo. Cada año se cosecha un promedio de 300 millones de tubérculos de papa, en 130 países. La República Popular China adiciona otros cinco millones de hectáreas del cultivo de papa. El bajo rendimiento y la poca extensión del cultivo de la papa en los países del Tercer Mundo, se deberia a la utilización errónea de variedades inapropiadas, adaptadas a climas templados del hemisferio norte, bajo diferentes condiciones a los trópicos bajos y subtrópicos. En los países cálidos, las plagas y enfermedades son problemas muy severos, especialmente en áreas donde los agricultores no pueden solventar a compra de pesticidas con precios exhorbitantes.

La hambruna catastrófica en los años 18461848 , en Irlanda y parte de Inglaterra, es un claro ejemplo de la estrecha o poca base genética de la papa en Europa, ya que se cultivaba millones de hectáreas de una sola variedad susceptible a la Rancha phythophtora infestans. Un millón de personas murieron de hambre y más de un millón migraron a los Estados Unidos. En aquella época, casi toda la pobla- ción de Irlanda dependía de la cosecha de papa, y en realidad era un monocultivo, basado en 2 ó 3 variedades en toda la isla. A mediados de 1846, apareció el hongo que produce la Rancha de la papa y, durante 3 años atacó los cultivos de papa con consecuencias catastróficas conocidas.

A consecuencia de ello, Inglaterra y Alemania, organizaron expediciones científicas a Latino américa, para encontrar fuentes de resistencia genética a esta enfermedad, habiendo encontrado en Mexico dos especies promisorias, el Solanum demisun con 72 cromosomas y el Solanum verrucosum con 24 cromosomas inmunes a la Rancha de la papa, incluso a la raza más virulenta de este hongo. Después de 50 años de mejoramiento en 1920 , se genera la primera variedad comercial en Europa, resistente a la enfermedad de la Rancha de la papa o Tizón Tardío. Posteriormente, durante los años 40 , se distribuía a todo el mundo, incluso al Perú, muchas variedades resistentes a esta enfermedad. Hoy en día cada una de las miles de variedades generadas poseen algunos genes de resistencia a la Rancha que provienen de esas dos especies silvestres Mexicanas. Estas dos especies habían evolucionado durante milenios y adquirido resistencia natural al hongo debido a que en la zona central de México, donde habitan, abundan todas las razas del hongo Phythophtora infestans. De esta manera los genes de resistencia de las papas silvestres y los genes virulentos del hongo evolucionaron paralelamente a travez del tiempo.

Los agricultores andinos, por el contrario, han cultivado por milenios un mosaico de variedades nativas, muchas de ellas de excelente textura y gusto. Un antropólogo ha detectado 46 variedades cultivadas de papa en una sola hectárea, en los Andes altos. Esto ha sido un medio para asegurar la cosecha, ya que, si una de las tantas variedades cultivadas es diezmada por una sola plaga, enfermedad o por factores extremos. las otras pueden sobrevivir y dar buena cosecha.

\section{SU POTENCIAL GENETICO}

Existen más de 160 especies tuberíferas silvestres de papa y ocho especies cultivadas. Estas especies silvestres se expanden solamente en América Latina, desde México hasta el Sur de Chile; desde el desierto costero peruano hasta las selvas húmedas del Brasil. Muchas especies habitan arriba de los 3,000 metros y algunos florecen y dan tubérculos al pie de los glaciales $(4,300 \mathrm{~m}$.) constituyendo los recursos genéticos más importantes para el mejoramiento de la papa cultivada.

El potencial genético de las especies silvestres del Perú y Bolivia es muy grande, estas especies 
contienen un cúmulo de genes útiles que pueden ser transferidos a las especies cultivadas de papa, mediante métodos convencionales y especiales de mejoramiento a corto y largo plazo. Así por ejemplo, la especie peruana Solanum acaule y la especie boliviana Solanum magistacrolobum tienen genes de resistencia a heladas y a muchas razas de virus que atacan a las cultivadas.

La introducción de material genético de especies silvestres, con relativa afinidad evolutiva a la papa cultivada, Solanum tuberosum, es considerada actualmente como un enorme potencial de mejoramiento. La papa cultivada generalmente, carece de caracteres fenotípicos deseables, que son encontrados en las especies afines, tales como la resistencia a plagas y enfermedades. Sin embrago, el éxito de la introducción de la variabilidad genética de una especie silvestre a la papa cultivada, depende de las afinidades citogenéticas. y taxonómicas. Cuanto más distante es la relación entre las especies, habrá más problemas para obtener híbridos de la primera generación. Si la especie donante y la especie receptora son muy afines y no hay restricciones en el apareamiento de cromosomas en la progenie, la transferencia de genes de una especie a otra, puede ser llevada a cabo con mucho exito por métodos convencionales de mejoramiento; tales como, cruzamientos dialéticos y retrocruzamientos a los genotipos parentales.

La papa es genética y taxonómicamente una planta cultivada compleja, donde se presenta una serie de poliploides que fluctúan desde especies diploides con 24 cromosomas, hasta especies exaploides con 72 cromosomas. Esta variabilidad en número de cromosomas, tanto en las especies cultivadas como en las especies silvestres, ha sido un factor limitante en la utilización ce material genético promisorio en programas de mejoramiento convencional.

Las especies diploides cultivadas, como la papa amarilla del Mantaro y las silvestres, son autoincompatibles; es decir, que rechazan su propio polen, y sólo aceptan y fecundan el polen de un clon extraño. Esta autoincompatibilidad se llama gametofítica, y es producto de la evolución de la papa hace millones de años. Las especies tetraploides, son en cambio, autoccmpatibles y fértiles; a este grupo pertenecen la mayoría de las papas comestibles como Mariva, Ccompis, Revolución.

Las papas triploides y pentaploides son estériles. Estas papas son las que se cultivan a 3,500 y 4,000 m.s.n.m. (Cusco y Puno) y son resistentes a heladas. Son las llamadas papas amargas, por su alto contenido del alcaloide solanina, no se pueden consumir directamente, sino ya deshidratada en forma de chuño negro o moraya.
Existen dos teorías acerca de la introducción de las primeras variedades a Europa: Unos manifiestan que las primeras variedades primitivas llevadas a Europa correspondían a la especie del grupo andigena, de días cortos, los cuales no tuberizaron en Europa, pero a través de numerosas generaciones de seedlings ó semilla botánica se adaptaron a fotoperiodos largos. Otros autores manifiestan que el material o germoplasma original llevado a Europa correspondería a la especia tuberosum que en aquél tiempo crecía en la zona de Chiloe y estaba adaptado a un clima similar al hemisferio norte (con cuatro estaciones bien marcadas). Recientes estudios citogenéticos, y filogenéticos indican que las papas del grupo andigena que fueron tempranamente domesticadas por las culturas pre-incas en su camino de expansión habrían sufrido una hibridación introgresiva con una especie diploide silvestre de la zona del Chaco, sudamericano, Solanum chacoense, de gran rendimiento. La papa del grupo andígena ya mezclada con sangre de $\mathbf{S}$. chacoense llegó a Chile y allí evolucionó y se adaptó al clima de esa región, el cual es muy parecido al clima europeo. Estas variedades adaptadas a días largos denominadas papas tuberosum habrían sido introducidas en Europa junto con las andígenas, pero fueron los clones tuberosum los que demostraron una mayor adaptación al clima y suelo europeo con altos rendimientos. Por lo tanto, muchas variedades actualmente mejoradas tendrían genes provenientes de las papas del grupo tuberosum y del grupo andígena ( ver cuadro evolutivo).

\section{SUS RECURSOS GENETICOS NATIVOS Y SILVES- TRES}

El género Solanum, a la cual pertenece la papa, es uno de los más extensos y complejos géneros dentro de la familia Solanaceae, conteniendo más de 2,000 especies, las cuales se extienden por todo el mundo, excepto en las zonas cerca a los polos. Existe una alta concentración de especies y variedades de Solanum en Sudamérica y Australia. Dentro de este genero hay más de 160 especies tuberíferas silvestres de papa y ocho especies cultivadas. Tanto las especies silvestres como las cultivadas están ubicadas dentro de la sección Petota de la familia Solanaceae. Afortunadamente la gran mayoria de las especies silvestres con su diversidad de ecotipos regionales, asi como las variedades nativas y primitivas de papa, han sido coletadas, catalogadas y almacenadas en los bancos de germoplasma, tanto de campo como in vitro, del Centro Internacional de la Papa (CIP). Este valioso recurso genético se encuentra disponible, no sólo para programas de mejoramiento, sino tambien para evaluaciones de interés regional.

Especies Silvestres,- Los Solanum tuberíferos constituyen un grupo taxonómico de plantas 
extremadamente complejo desde el punto de vista genético y taxonómico. Debido a la gran variabilidad genética que presentan ha sido difícil clasificarlos y agruparlos en grupos identificables. Sin embargo hoy en dia se sabe que las 164 especies de papa silvestre y cultivada están agrupadas en 18 series. Se menciona a continuación algunas series importantes.

Serie ETUBEROSA La serie etuberosa engloba especies diploides muy primitivas, arbustivas y perennes. Ninguna especie tuberiza y es autocompatible, es decir se autopolinizan. Son especies altamente resistentes a los virus del enrrollamiento de la papa y al mosaico, además toleran bajas temperaturas, habitan en los bosques frios y humedos del Sur de Chile. El cruzamiento con las especies cultivadas requiere métodos no convencionales. Las especies que mas aportaron genes útiles a las cultivadas son: $\mathbf{S}$. etuberosun y $\mathbf{S}$.

brevidens

Serie JUGLANDIFOLIA.- Constituida por especies diploides muy primitivas arbustiva y perennes, no tuberizan y todas tienen flores amarillas. Filogenéticamente se acercan al tomate, con el cual también han logrado hibridarse, aunque con extrema dificultad. Contienen genes de resistencia a salinidad, tal como S. licopersicoides (Laguna de Aricota) $\mathbf{S}$. rickii en el desierto de Atacama (Arica). Las especie arbustiva S. ochrantum habita en la ceja de selva peruana $(2000-2500 \mathrm{~m}$.) y tienen genes de resistencia a marchitamiento bacteriano.

Serie DEMISSA.- Especies mexicanas mayormente hexaploides $(6 \mathrm{X})$ altamente resistentes a la rancha de la papa. Los genes de $\mathbf{S}$. demissum han sido incorporados a clones o cultivares avanzados. Hoy en día muchas variedades de alto rendimiento de papa tienen genes de resistencia horizontal y vertical a la rancha $\mathbf{P}$. infestans provenientes de $\mathbf{S}$. demissum de México.

Serie TUBEROSA.- En esta serie se encuentran cerca de 50 especies silvestres de papa y ocho cultivadas. Todas guardan mucha afinidad entre sí. Sin embargo, existen unas pocas especies no muy cercanas a las papas cultivadas. Cabe destacar $\mathbf{S}$. sparsipilum, $2 X$, una especie silvestre boliviana que ha contribuido genes de resistencia a la mancha bacteriana en clones de papas adaptadas al trópico medio bajo.

Papas cultivadas: Bukasov, Hawkes, Ochoa y otros autores establecen una serie de poliploidia y taxonomía de las papas nativas cultivadas:

Diploides: S. stenotonum, $2 n=2 x=24=A A$, una de las especies que muestra una enorme variabilidad genética, cultivada en los andes altos, $\mathbf{S}$. goniocalyx, con muy pocas variedades, siendo una de ellas la famosa papa amarilla del centro del Perú. $\mathbf{S}$. phureja, domesticada en la zona de los páramos húmedos y templados de Colombia, se caracteriza por la ausencia de una marcada latencia de sus tubérculos y también por precocidad. S. ajanhuiri, Similar a las anteriores pero resistentes a heladas. Fue domesticada en el Altiplano boliviano, se cree que provienen de la hibridación Interspectiva y natural de S. stenotomum X. S. megistacrolobum.

Dentro del grupo de los diploides se pueden también considerar las papas haploides o dihaploides con 24 cromosomas, mantenidos en bancos genéticos para su utilización en mejoramiento de clones avanzados. Los haploides no constituyen variedades 0 cultivares populares, más bien son "puentes genéticos" o progenitores en las hibridaciones avanzadas de papa. Los haploides se caracterizan por su alto grado de homocigocidad y son obtenidos artificialmente por haploidización sexual y cultivo in vitro de anteras de cultivares tetraploides. Muchos haploides son utilizados en cruzamientos interploidiales $(4 x-2 x)$ debido a su producción de gametos no reducidos (polen $2 n-F D R$ ) el cual confiere una alta heterosis a la progenie $4 x$ resultante. Asimismo se ha experimentado exitosamente que los haploides tuberosum (2x) son puentes excelentes para transferir genes de especies silvestres diploides en cruzamientos $2 x$ por $2 x$. La progenie $2 x$ resultante puede ser elevada a $4 x$ utilizando los gametos $2 n$ de los haploides hibridos.

TRIPLOIDES.- Son papas estériles por su ploidia impar $(2 n=3 x=36)$, lo cual dificulta el apareamiento de cromosomas homólogos en la meiosis. La especie, más conocida en el centro y sur del Perú es Solanum chaucha, la cual es el resultado de una hibridación natural de S.tuberosum $(2 n=4 x=48)$ por la especie diploide $S$. stenotomum $(2 n=2 x=24)$. La variedad de mayor popularidad y comercialización es la Huayro. En el Altiplano peruano-boliviano se cultiva intensivamente desde hace miles de años la especie Triploide Solanum juzecpzukii. Las clones o variedades de esta especie son conocidas como papas amargas y se cultivan en promedio a 4,000 m.s.n.m. De estas variedades se elabora el chuño y la moraya por congelación y subsecuente deshidratación. Estas variedades no pueden sancocharse y consumirse directamente debido a su alto contenido de alcaloides solanina el cual es tóxico para la salud humana. Pero se se consume en forma deshidratada donde se elimina gran parte de la solanina glycoalcaloide. El origen y evolución de $\mathbf{S}$. juzecpzukii es muy interesante y misterioso. Evidencias citogenéticas y agrobotánicas 
indican que se originó en el Altiplano por hibridación natural de la especie cultivada diploide $S$. stenotomum $(2 n=2 x=24)$ y la especie altoandina silvestre $S$. acaule $(2 n=4 x=48)$. La especie cultivada aportó caracteres agronómicos al híbrido, tales como la alta tuberización y rendimiento mientras que la silvestre fue el donante de genes de alta resistencia a heladas y a los virus $X$ y $Y$ de la papa, además del alto contenido del solanina. S. juzecpzukii constituye un gran aporte a la adaptación y coexistencia del habitante colla y aymara del altiplano, el cual influyó enormemente en su temprana evolución a través de conscientes e inconscientes selecciones orientadas a obtener variedades resistentes a heladas en zonas marginales donde todas las especies y variedades de papa cultivadas sucumben a las condiciones extremas del medio altoandino.

TETRAPLOIDES.- Más del $50 \%$ del caudal genético de la papa corresponde a variedades tetraploides $(2 n=4 x=48)$ englobadas en dos sub especies: Solanum tuberosum Ssp andígena y $\mathbf{S}$. tuberosum ssp tuberosum. Esta especies tiene una gran distribución en los Andes, desde Ecuador hasta Bolivia. Sus variedades son de gran rendimiento y amplia adaptación. Las papas tetraploides andígena se originaron por ploidinización natural (FDR) a partir de sus antecesores primitivos diploides. Las papas tuberosum se originaron en el sur de Chile y en su evolución migratoria de andígena se hibridizó con la especie diploide silvestre del Chaco boliviano, $\mathbf{S}$. chacoense Este hibrido interespecifico migro al sur hasta llegar a Chile adaptándose a días largos de verano e inviernos muy fríos de días cortos. Las papas andígenas se caracterizan generalmente por su gran adaptación, alta variabilidad genética, fertilidad y tolerancia a plagas y enfermedades. Las papas tuberosum tienen una base genética más angosta y son de altos rendimientos y uniformidad y su relativa susceptibilidad a plagas y enfermedades además de su baja fertilidad.

Ultimas observaciones de la variabilidad genética del germoplasma nativo en el Altiplano Boliviano realizadas por el Profesor Ramiro Ortega (comunicacion personal), indican la existencia de papas amargas tetraplnides del grupo andigena $(2 n=4 X=48)$. Posiblemente se trata de genotipos segregantes de la especie pentaploide $\mathbf{S}$. curtilobum y domesticados por los Aymaras del Altiplano Boliviano.

PENTAPLOIDES.- Los recursos genéticos de papas pentaploides $(2 n=5 x=60)$ son muy escasos y todos pertenecen a la especie altoandina del Altiplano peruano-boliviano Solanum curtilobum. Esta especie al igual que $\mathbf{S}$. juzecpzukii forma parte del acerbo genético de las papas amargas y se cultivan para la 90 elaboración de chuño y moraya. Solanum curtilobum evolucionó en el altiplano Peruano - Boliviano a 4,000 $\mathrm{m}$. de altitud, a partir de hibridaciones naturales entre la papa tetraploide. S. tuberosum ssp andigena y la triploide S. juzecpzukii. El progenitor del grupo andigena aportó genes de alto rendimiento mientras que la triploide aportó genes de resistencia a heladas y mayor contenido de solanina. S. curtilobum se diferencia agronómicamente de $\mathbf{S}$. juzecpzukii por su mayor rendimiento, mayor tamaño de tubérculos y follaje y menor grado de resistencia a heladas comparado con $\mathbf{S}$. juzecpzukii ( ver esquema).

HEXAPLOIDES: Al igual que los haploides sólo existen bancos de genes y no como cultivares. Sin embargo existen especies afines silvestres que se utilizan sistemáticamente en mejoramiento como fuente de genes de resistencia a hongos, nematodos y virus que destruyen los cultivos de papa. Estos son : Solanum demisum y S. hougasii de la Serie DEMISA y el citotipo hexaploide de S. acaule. La especie hexaploide del Nor Este de Argentina S. oplocence, muy utilizada por sus genes de resistencia I nematodo de la papa Globodera pallida. La especie $\mathbf{S}$. tuberosum ssp andigena se habria hibridizado naturalmente en sus caminos migratorios por el cono Sur de Sudamerica con S. oplocense, adquiriendo de esta forma resistencia al nematodo G. pallida.

Finalmente, el inmenso caudal de genes útiles de las papas silvestres y cultivadas vienen siendo explotados intensivamente desde el tiempo de los incas hasta nuestros días para generar nuevas variedades (nativas) o clones superiores (variedades modernas) adaptadas a las diversas condiciones agroecologicas del Tercer Mundo. Este caudal de genes constituye para los fitomejoradores modernos una fuente inagotable de recursos geneticos valiosos.

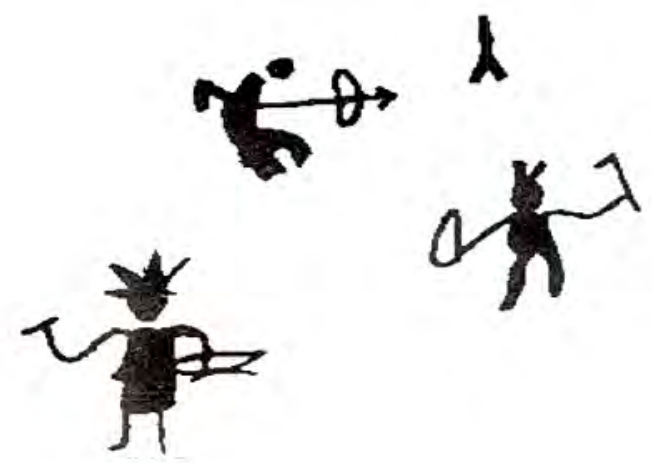


ESQUEMA DE LOS CAMINOS EVOLUTIVOS DE LA PAPA CULTIVADA

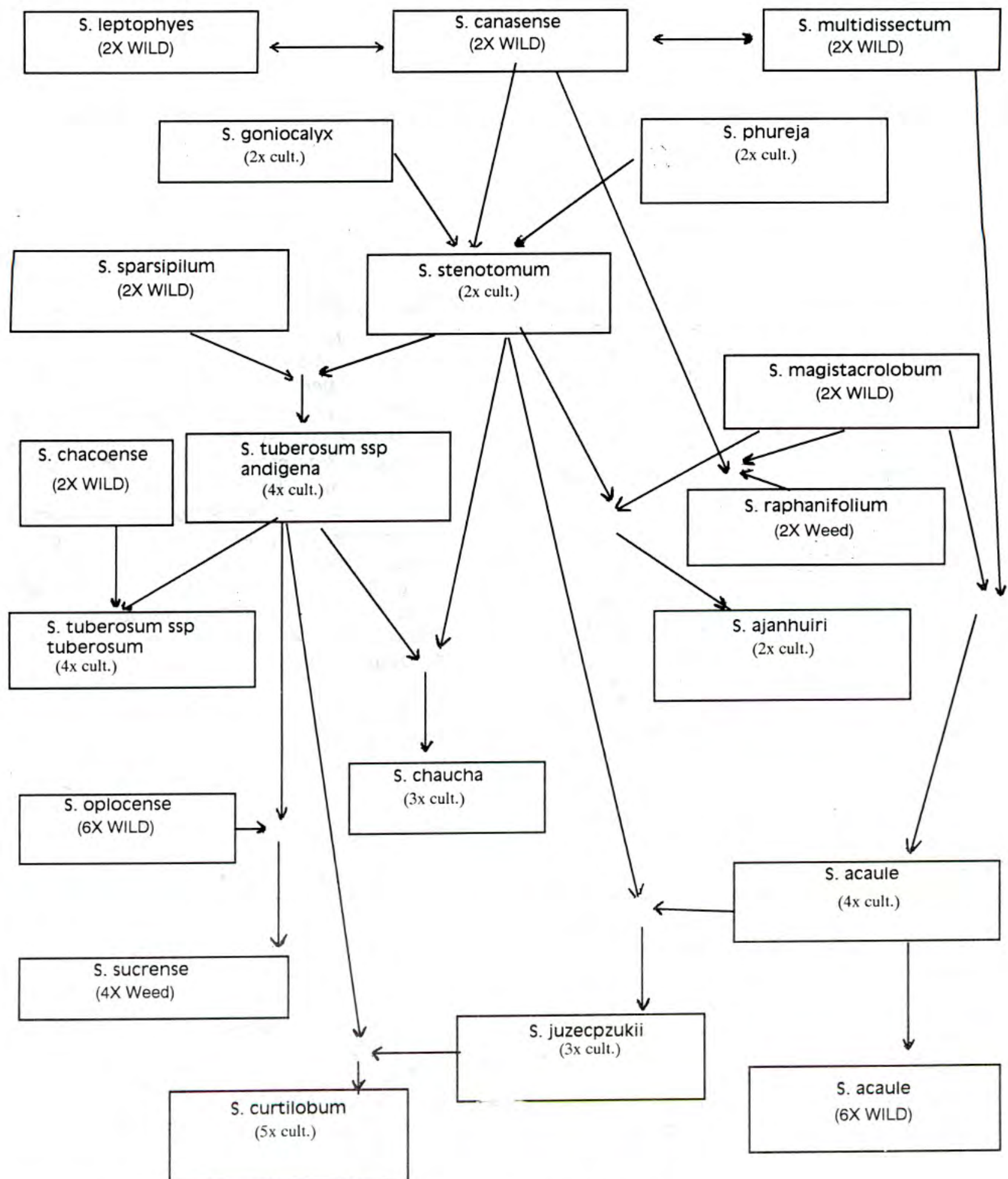

$2 n=2 x=24$

G: $2 n$ = Producción de Gametos 2n (doble números de cromosomas) Wild $=$ Especie primitiva silvestre
Cult $=$ Especie cultivada Weed $=$ Especie maleza 